\title{
The newly synthesized thiazole derivatives as potential antifungal compounds against Candida albicans
}

\author{
Anna Biernasiuk ${ }^{1}$ (1) Anna Berecka-Rycerz ${ }^{2} \cdot$ Anna Gumieniczek $^{2} \cdot$ Maria Malm $^{3} \cdot$ Krzysztof Z. Łączkowski $^{4}$. \\ Jolanta Szymańska ${ }^{5} \cdot$ Anna Malm ${ }^{1}$
}

Received: 13 February 2021 / Revised: 15 July 2021 / Accepted: 19 July 2021 / Published online: 19 August 2021

(c) The Author(s) 2021

\begin{abstract}
Recently, the occurrence of candidiasis has increased dramatically, especially in immunocompromised patients. Additionally, their treatment is often ineffective due to the resistance of yeasts to antimycotics. Therefore, there is a need to search for new antifungals. A series of nine newly synthesized thiazole derivatives containing the cyclopropane system, showing promising activity against Candida spp., has been further investigated. We decided to verify their antifungal activity towards clinical Candida albicans isolated from the oral cavity of patients with hematological malignancies and investigate the mode of action on fungal cell, the effect of combination with the selected antimycotics, toxicity to erythrocytes, and lipophilicity. These studies were performed by the broth microdilution method, test with sorbitol and ergosterol, checkerboard technique, erythrocyte lysis assay, and reversed phase thin-layer chromatography, respectively. All derivatives showed very strong activity (similar and even higher than nystatin) against all $C$. albicans isolates with minimal inhibitory concentration $(\mathrm{MIC})=0.008-7.81 \mu \mathrm{g} / \mathrm{mL}$ Their mechanism of action may be related to action within the fungal cell wall structure and/or within the cell membrane. The interactions between the derivatives and the selected antimycotics (nystatin, chlorhexidine, and thymol) showed additive effect only in the case of combination some of them and thymol. The erythrocyte lysis assay confirmed the low cytotoxicity of these compounds as compared to nystatin. The high lipophilicity of the derivatives was related with their high antifungal activity. The present studies confirm that the studied thiazole derivatives containing the cyclopropane system appear to be a very promising group of compounds in treatment of infections caused by C. albicans. However, this requires further studies in vivo.
\end{abstract}

\section{Key points}

- The newly thiazoles showed high antifungal activity and some of them - additive effect in combination with thymol.

- Their mode of action may be related with the influence on the structure of the fungal cell wall and/or the cell membrane.

- The low cytotoxicity against erythrocytes and high lipophilicity of these derivatives are their additional good properties.

Graphical abstract

Keywords Thiazole $\cdot$ Antifungal activity $\cdot$ Candida albicans $\cdot$ Mode of actions $\cdot$ Interactions $\cdot$ Lipophilicity

\section{Introduction}

Over the past years, the occurrence of systemic, lifethreatening fungal infections caused by Candida spp. has increased dramatically, especially in patients with altered immune system (Houšl et al. 2020; Pristov and Ghannoum

Anna Biernasiuk

anna.biernasiuk@umlub.pl

Extended author information available on the last page of the article
2019). Besides, these yeast species may be etiological agents of superficial infections. The predominant cause of all types of candidiases is Candida albicans - simultaneously, the fourth most common etiological factor of hospital acquired infections. It is associated with the occurrence of mortality rates as high as $35-50 \%$ (Roemer and Krysan 2014; Turecka et al. 2018). Other emerging Candida species - non-albicans Candida spp. (NAC) like C. glabrata, C. krusei, or C. parapsilosis - are also serious nosocomial threats (Silva et al. 2017; Sun et al. 2015). Currently, the list of the commertially available antifungal 
agents, used for the treatment of infections caused by Candida spp., is limited to three major classes: polyenes (e.g., amphotericin B or nystatin), azoles (e.g., fluconazole or posaconazole), and echinocandins (e.g., caspofungin or micafungin) (Sharma et al. 2016; Roemer and Krysan 2014; Turecka et al. 2018). Their mechanisms of action in the fungal cell are different: polyenes bind fungal cell membrane ergosterol leading to cell lysis; azoles inhibit ergosterol biosynthesis with fungistatic activity and echinocandins block fungal $(1,3)-\beta$-D-glucan cell wall synthesis exhibiting fungicidal effect. Moreover, the candidiases are difficult to treat due to resistance to many antimycotics, especially azoles (Sharma et al. 2016; Silva et al. 2017; Turecka et al. 2018).

The desire to simplify traditional therapy method in which the drug mixture is used has led scientists to create hybrid drugs in which two or more pharmacophores have been combined into one structure of a new drug. This combination leads to a drug that is characterized by a higher activity, metabolic stability, ability to penetrate through various biological membranes, and reducing the microbial resistance (Viegas-Junior et al. 2007). For many years, thiazole derivatives have been widely studied due to their broad spectrum of activity, such as antimicrobial (Carradori et al. 2013; Chhabria et al. 2016; Łączkowski et al. 2016, 2017), anticancer (Gomha et al. 2016; Donarska et al. 2021; Piechowska et al. 2019), anti-Plasmodium falciparum (Makam et al. 2014), anti-Trypanosoma cruzi (de Oliveira Filho et al. 2017), anticonvulsant (Siddiqui et al. 2020), antioxidant (Salar et al. 2019) as well as anti-SARS-CoV-2 (Konno et al. 2013; Abu-Melha et al. 2020). It has been shown in literature that the thiazole scaffold is an excellent pharmacophore that can be used to develop new antimicrobial. In the last years, the cyclopropane system enjoys great interest in the drug design, and it can be found in eight of the top 200 bestselling drugs approved by the Food and Drug Administration (FDA) (Talele 2016). The cyclopropane rings are preferably used as replacements for alkyl chains, for example, the gemdimethyl (Wood et al. 2006), and alkene groups (Hopkins et al. 2011), and as a substitute of phenyl ring (Abe et al. 2011) in order to increase the metabolic stability or reduce lipophilicity of the drugs. Unique properties of the cyclopropane ring are due to its planarity, low molecular weight, and conformational rigidity. Recently, series of thiazole derivatives containing the cyclopropane system, showing very high activity against Candida spp., has been developed. Their activity was comparable and even higher than that of nystatin $(\mathrm{MIC}=0.015-7.81 \mu \mathrm{g} / \mathrm{mL}$ ). The toxicity studies on cell lines showed that Candida spp. growth was inhibited at non-cytotoxic concentrations (Łączkowski et al. 2018).

In the present work, we verified the antifungal activity of the newly synthesized thiazole derivatives against clinical $C$. albicans strains. In addition, we examined their mechanism of antifungal action on fungal cell and the effect in combination with selected antimycotics. This work also conducted tests to assess the toxicity of these compounds to erythrocytes and their lipophilicity.

\section{Materials and methods}

\section{Chemicals}

The nine newly synthesized (2-(cyclopropylmethylidene) hydrazinyl)thiazole derivatives that showed very high activity against reference and clinical isolates of Candida spp. in our previous studies (Łączkowski et al. 2018) were further evaluated for their biological activity. The structure of the developed thiazoles (T1-T9) was presented in Fig. 1, while their synthesis and all components necessary for this synthesis (Sigm-Aldrich Chemicals, St. Louis, MO, USA) were described elsewhere (Eączkowski et al. 2018).

\section{Microorganisms}

Two references strains of yeasts from American Type Culture Collection (ATCC): Candida albicans ATCC 2091 and Candida albicans ATCC 10231 were included. Moreover, 30 clinical isolates of $C$. albicans were used. These microorganisms were isolated from oral cavity of hospitalized patients with hematological malignancies (from the collection of clinical strains deponded in Department of Pharmaceutical Microbiology of Medical University in Lublin, Poland). The Ethical Committee of the Medical University of Lublin approved the study protocol (No. KE-0254/75/2011). The isolates were identified by standard diagnostic methods: microscopic, macroscopic, and biochemical microtest, e.g., API 20 C AUX, ID 32 C, API Candida (bioMèrieux, France) on the basis of assimilation of various substrates (Biernasiuk et al. 2018; Łączkowski et al. 2018). Strains were stored as glycerol stock at $-70^{\circ} \mathrm{C}$. For research purposes, fungal cultures were conducted at $35^{\circ} \mathrm{C}$ for $24 \mathrm{~h}$ on Sabouraud agar (BioMaxima S.A., Lublin, Poland).

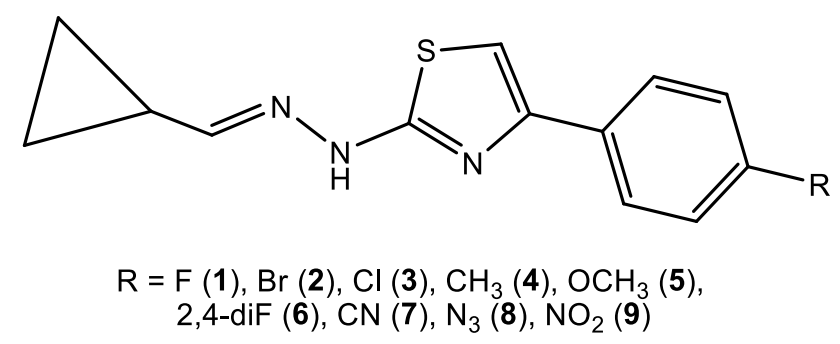

Fig. 1 The newly synthesized thiazole derivatives with high activity against Candida spp 


\section{Antifungal activity assay}

To verify antifungal activity of the newly synthesized thiazole derivatives against clinical strains of $C$. albicans, the broth microdilution method was used according to European Committee on Antimicrobial Susceptibility Testing (EUCAST) (2003) and Clinical and Laboratory Standards Institute (CLSI) guidelines (2012). These assays were performed as described previously (Biernasiuk et al. 2018; Łączkowski et al. 2018). The samples containing $10 \mathrm{mg}$ of studied compounds were dissolved in $1 \mathrm{~mL}$ dimethylsulphoxide (DMSO). The MIC (Minimal Inhibitory Concentration) of the compounds was examined using their two-fold dilutions in RPMI 1640 broth (Sigma-Aldrich Chemicals, St. Louis, MO, USA) with MOPS (3-(N-Morpholino)propanesulfonic acid) (Sigma-Aldrich Chemicals, St. Louis, MO, USA), prepared in 96-well polystyrene plates. Final concentrations of the thiazole derivatives ranged from 0.002 to $1000 \mu \mathrm{g} / \mathrm{mL}$. All of the used isolates of C. albicans were first subcultured on Sabouraud agar at $37{ }^{\circ} \mathrm{C}$ for $24 \mathrm{~h}$. The fungal suspensions were prepared in sterile saline $(0.85 \% \mathrm{NaCl})$ with an optical density of McFarland standard scale 0.5 - approximately $5 \times 10^{5} \mathrm{CFU} / \mathrm{mL}$ (Colony Forming Units $/ \mathrm{mL}$ ). Next, to each well containing $100 \mu \mathrm{L}$ of RPMI 1640 broth with MOPS and the above various concentrations of tested compounds, $1 \mu \mathrm{L}$ of the appropriate fungal suspension was added. After incubation $\left(37^{\circ} \mathrm{C}, 24 \mathrm{~h}\right)$, the MIC was assessed spectrophotometrically as the lowest concentration of the samples showing complete fungal growth inhibition. The DMSO, growth, and sterile controls were also carried out. Moreover, their MIC was assessed spectrophotometric as the lowest concentration of the samples showing complete fungal growth inhibition. The standard antifungal antibiotic - nystatin (Sigma-Aldrich, Chemicals, St. Louis, MO, USA) was used as positive control. In turn, the MFC (Minimal Fungicidal Concentration) defined as the lowest concentration of the compounds was required to kill a particular fungal species. MFC was determined by removing the culture using for MIC determinations from each well and spotting onto Sabouraud agar medium. Then, the plates were incubated in the appropriate conditions (as before). The lowest compound concentrations with no visible growth observed were assessed as a fungicidal concentration. All the experiments were repeated three times, and representative data are presented. In this study, very strong bioactivity was defined as a MIC $<10 \mu \mathrm{g} / \mathrm{mL}$. Moreover, the MFC/MIC ratios were also calculated in order to determine fungicidal $(\mathrm{MFC} / \mathrm{MIC} \leq 4)$ or fungistatic $(\mathrm{MFC} / \mathrm{MIC}>4)$ effect of the studied thiazole derivatives (O'Donnell et al. 2010; Wiegand et al. 2008).

\section{Mode of action}

Sorbitol assay To evaluate the effect of the newly synthesized thiazole derivatives on the cell wall of C. albicans, the sorbitol assay was performed. The sorbitol (Sigma-Aldrich Chemicals, St. Louis, MO, USA), as an osmotic protector, was added to the culture medium in a final concentration of $0.8 \mathrm{M}$. The MIC of the tested compounds using Sabouraud Dextrose Broth (SDB) medium (BioMaxima S.A., Lublin, Poland) with and without sorbitol (control) against yeasts was determined in different lines of the same microplate. The test was performed using the microdilution technique in triplicate according to the previous guidelines (O'Donnell et al. 2010; Wiegand et al. 2008). After filling each well of the microplates with $100 \mu \mathrm{L}$ of SDB and $100 \mu \mathrm{L}$ of SDB supplemented with sorbitol, serial dilutions of newly thiazole derivatives and nystatin (as control) ranging from 0.004 to $1000 \mu \mathrm{g} / \mathrm{mL}$ were carried out. Subsequently, $10 \mu \mathrm{L}$ of yeast suspension $\left(10^{6} \mathrm{CFU} / \mathrm{mL}\right)$ was added to each well. Yeast growth and sterility control were also performed. The plates were incubated at $37{ }^{\circ} \mathrm{C}$ and read after 2 and 7 days. MICs were defined as the lowest concentrations of tested compounds capable of visually inhibiting the candidal growth. Sorbitol assay was prepared in accordance with the procedure showed by other authors (Castro and Lima 2013; Leite et al. 2014; Lima et al. 2012; de Oliveira Filho et al. 2016; Rajkowska et al. 2016; Turecka et al. 2018).

Ergosterol assay To assess if the newly synthesized thiazole derivatives bind to the fungal membrane sterols, this experiment was performed. The stock solution of exogenous ergosterol (Sigma-Aldrich Chemicals, St. Louis, MO, USA) at final concentration $10 \mathrm{mg} / \mathrm{mL}$ was prepared at the time of the experiment. Ergosterol was first pulverized in the pre-sterilized porcelain mortar and dissolved in DMSO (no more than $10 \%$ of final volume) with addition $1 \%$ Tween 80 (Pol-Aura, Różnowo, Poland). The formed emulsion was then homogenized, heated to augment the solubility, and diluted with the liquid culture medium (in $89 \%$ of the final volume of liquid medium). The MIC of tested compounds against $C$. albicans was determined by using broth microdilution techniques according to the previous guidelines (O'Donnell et al., 2010; Wiegand et al. 2008) in the presence and absence of exogenous ergosterol, added to the assay medium, in different lines of the same microplate. The ergosterol was transferred to the wells in a final concentrations of 100,200 , and $400 \mu \mathrm{g} / \mathrm{mL}$. After filling each well of the microplates with $100 \mu \mathrm{L}$ of RPMI- 1640 medium with and without ergosterol, serial dilutions of newly thiazole derivatives and nystatin (as positive control) ranging from 0.002 to $1000 \mu \mathrm{g} / \mathrm{mL}$ were carried out. Then, $10 \mu \mathrm{L}$ of yeast suspension $\left(10^{6} \mathrm{CFU} / \mathrm{mL}\right)$ was added to each well. The plates were incubated at $36^{\circ} \mathrm{C}$ for $24 \mathrm{~h}$ and MIC was 
determined as the lowest concentration of tested compounds inhibiting the visible growth of $C$. albicans. Yeast growth and sterility were also controlled. Ergosterol assay was prepared according to the procedure described by other authors (Castro and Lima 2013; Leite et al. 2014; Lima et al. 2012; de Oliveira Filho et al. 2016; Rajkowska et al. 2016; Turecka et al. 2018).

\section{Investigation of interaction of the newly synthesized thiazole derivatives and selected antimycotics}

To determine the fractional inhibitory concentrations (FICs) of the newly synthesized thiazole derivatives in combination with other antifungal substances, a checkerboard technique (according to CLSI) was used in 96-well microtiter plates. The different antimycotics for these studies were used: antifungal antibiotic - nystatin, synthetic antiseptic - chlorhexidine, and natural compound - thymol (Sigma-Aldrich Chemicals, St. Louis, MO, USA). The tested thiazole derivatives and selected antimycotics in specific concentrations (estimated at their respective MIC values) were used. These substances at various concentrations in the broth corresponding: $8 \times \mathrm{MIC}, 4 \times \mathrm{MIC}, 2 \times \mathrm{MIC}$, MIC, $1 / 2 \times \mathrm{MIC}$, $1 / 4 \times$ MIC, and $1 / 8 \times$ MIC (from eight times greater than their MIC to eight times lower than their MIC), were added horizontally (studied compounds) and vertically (selected antifungals) to the wells of the plate. Finally, the reference C. albicans inoculum was added to per each well in the plate. Growth and sterility controls were also performed. Next plates were incubated at $35^{\circ} \mathrm{C}$ for $24 \mathrm{~h}$. Each test was performed in triplicate (Blanco et al. 2017; Castro and Lima 2013; Turecka et al. 2018). After describing the MIC for each row, the FIC and $\Sigma$ FIC (FIC index) were calculated as $\Sigma$ FIC $=$ FICA + FICB $=(\mathrm{CA} / \mathrm{MICA})+(\mathrm{CB} / \mathrm{MICB})$, where MICA and MICB are the $\mathrm{MIC}_{\mathrm{S}}$ of compounds $\mathrm{A}$ (new thiazole derivatives) and $\mathrm{B}$ (selected antimycotics) alone, respectively. In turn, $\mathrm{CA}$ and $\mathrm{CB}$ are the concentrations of the studied compounds: $\mathrm{A}$ in combinations with $\mathrm{B}$ and $\mathrm{B}$ in combinations with A, respectively. FICI - FIC index values were interpreted as follows: FICI values of $\leq 0.5$ as synergy, FICI values between 0.5 and 1 as additive, FICI values between 1 and 4 as indifferent, and FICI values $>4$ as antagonism (Blanco et al. 2017; Castro and Lima 2013; Turecka et al. 2018).

\section{Erythrocyte lysis assay}

The erythrocyte lysis assay (ELA) was performed to study the toxicity of the newly synthesized thiazole derivatives on red blood cells. In the first, erythrocytes were harvested from $5.0 \mathrm{~mL}$ fresh sheep blood (BioMaxima S.A., Poland) by centrifugation for $10 \mathrm{~min}$ at $1000 \times \mathrm{g}$ and washed three times with $0.85 \% \mathrm{NaCl}$. Subsequently, $2 \%$ erythrocyte suspension was prepared in sterile phosphate buffer saline and in a volume of $100 \mu \mathrm{L}$ was added to each well of a 96-well microtiter plate. The serial dilutions of the thiazole derivatives ranging from 0.48 to $1000 \mu \mathrm{g} / \mathrm{mL}$ were performed. For comparison purposes, nystatin as standard antimycotic in the same concentration range was also examined. To estimate the relative hemolytic potential of the tested compounds, the appropriate controls, i.e., $100 \%$ erythrocyte lysis using $4 \%$ Triton X-100 (Pol-Aura, Różnowo, Poland) and 0\% lysis in saline solution, were used. Plates with samples were incubated for 1 hour at $37{ }^{\circ} \mathrm{C}$, then centrifuged for $10 \mathrm{~min}$ at $1000 \times \mathrm{g}$ to separate the unlysed erythrocytes, and subsequently, the supernatant was transferred to a new plate. The absorbance was measured spectrophotometrically at 450 $\mathrm{nm}$. The ELA represents an advantageous bioassay, because the lytic response can be measured photometrically by the amount of released hemoglobin. The hemolysis percentage was calculated according to the equation: $\%$ hemolysis = [(A450 of test compound treated sample-A450 of buffer treated sample)/(A450 of $4 \%$ Triton X-100 treated samplesA450 of buffer treated sample) $] \times 100$ (Eschbach et al. 2001; Silva et al. 2017; Turecka et al. 2018; Zohra and Fawzia 2014).

\section{Lipophilicity}

Experimental lipophilicity of the newly synthesized thiazole derivatives was determined using reversed phase thin-layer chromatography on $10 \times 10 \mathrm{~cm}$ plates coated with $\mathrm{C} 18$ silica (HPTLC silica gel RP18 $\mathrm{F}_{254}$ from E. Merck, Darmstadt, Germany). Binary eluents were prepared by mixing appropriate volumes of water and one of the following organic modifiers in volumes increasing by $5 \%$ (50-70\% of 1,4-dioxane, $50-80 \%$ of acetonitrile, $55-75 \%$ of acetone and $65-90 \%$ of methanol). All organic modifiers were of analytical grade, and they were supplied by POCH (Gliwice, Poland). The reference substances with known lipophilicity were 2-aminophenol (S1), benzocaine (S2), 2-ethyl hydroxybenzoate (S3), phenyl salicylate (S4), and 3,4-benzopyrene (S5) (Sigma-Aldrich Chemicals, St. Louis, MO, USA; Fluka, Germany and POCH, Gliwice, Poland).

The studied thiazole derivatives and the reference substances (S1-S5) were dissolved in methanol to obtain the concentration of $2.0 \mathrm{mg} / \mathrm{mL}$. From these working solutions, volumes of $0.2 \mu \mathrm{L}$ were spotted to the plates. The chromatograms were developed to a distance of $8 \mathrm{~cm}$ from the origin, in horizontal teflon chambers with an eluent distributor (Chromdes, Lublin, Poland) at constant temperature of 23 $\pm 1{ }^{\circ} \mathrm{C}$. After developing of the chromatograms, the spots of the substances were localized under ultraviolet illumination at $254 \mathrm{~nm}$. 
On the basis of retardation coefficients $\left(R_{F}\right)$ obtained from the chromatograms, the $R_{M}$ values for the reference substances and the thiazole derivatives were calculated using the following equation: $R_{M}=\log \left(1-R_{F} / R_{F}\right)$. Then, $R_{M 0}$ values (equivalent to the retention of an analyte extrapolated to $100 \%$ water as eluent) were calculated using the following equation: $R_{M}=R_{M 0}-S \varphi$, where $\varphi$ is the volume fraction of the organic modifier in the eluent and $S$ is the slope of respective regression curve. The calculated $R_{M 0}$ values for the reference substances were correlated with their log $P$ values found in the literature (Komsta et al. 2010) and linear calibration curves were obtained for all organic modifiers, i.e., 1,4-dioixane, acetone, acetonitrile, and methanol. Lipophilicity of the newly synthesized thiazole derivatives was calculated using their $R_{M 0}$ values on the basis of these calibration equations.

\section{Data analysis}

All the samples were analyzed in triplicate, and representative data (mode) are presented.

\section{Results}

\section{Antifungal activity}

Taking into account the results presented earlier (Łączkowski et al. 2018), the newly synthesized (2-(cyclopropylmethylidene)hydrazinyl)thiazole derivatives showed very strong activity (MIC $<10 \mu \mathrm{g} / \mathrm{mL}$ ) towards two reference Candida albicans ATCC 2091 and Candida albicans ATCC 10231 strains (with MIC $=0.015-3.91 \mu \mathrm{g} / \mathrm{mL})\left(\mathrm{O}^{\prime}\right.$ Donnell et al., 2010; Wiegand et al. 2008). Moreover, MFC values were also very high, in the range $0.015-15.62 \mu \mathrm{g} / \mathrm{mL}$. Therefore, this study aimed to confirm the activity of these substances against 30 clinical isolates of $C$. albicans from the oral cavity of hospitalized patients with hematological malignancies.
These patients are particularly vulnerable to infections, and C. albicans is the main etiological factor of candidiasis.

According to distribution of MIC and MFC values among clinical isolates (Figure S1) and data presented in Table 1, the assayed thiazole derivatives showed very strong antifungal effect towards these strains with MIC $=0.008-7.81 \mu \mathrm{g} /$ $\mathrm{mL}$, dependent on the compound. The values of MFC were 2-4-fold higher $(\mathrm{MFC}=0.015-31.25 \mu \mathrm{g} / \mathrm{mL}$ ) than MIC values. In addition, the $\mathrm{MIC}_{50}$ or $\mathrm{MIC}_{90}$ values for these compounds were calculated, defined as the minimum concentrations inhibiting the growth of $50 \%$ or $90 \%$ of all tested strains, respectively. These values were $\mathrm{MIC}_{50}=0.12-1.95$ and $\mathrm{MIC}_{90}=0.24-3.91 \mu \mathrm{g} / \mathrm{mL}$. In turn, $\mathrm{MFC}_{50}$ and $\mathrm{MFC}_{90}$ values were described as the lowest concentrations required to kill $50 \%$ or $90 \%$ of the 30 clinical C. albicans isolates $\left(\mathrm{MFC}_{50}=0.24-7.81\right.$ and $\left.\mathrm{MIC}_{90}=0.48-15.62 \mu \mathrm{g} / \mathrm{mL}\right)$.

The highest activity showed thiazole derivatives T2, T3, and T4 with MIC $=0.008-0.98 \mu \mathrm{g} / \mathrm{mL}, \mathrm{MIC}_{50}=0.12$ $\mu \mathrm{g} / \mathrm{mL}$, and $\mathrm{MIC}_{90}=0.24-0.48 \mu \mathrm{g} / \mathrm{mL}$. The compounds T1, T5, T6, T8, and T9 exhibited also strong, but slightly lower activity compared to the above mentioned derivatives $\left(\mathrm{MIC}=0.015-3.91 \mu \mathrm{g} / \mathrm{mL}, \mathrm{MIC}_{50}=0.48-0.98 \mu \mathrm{g} / \mathrm{mL}\right.$ and $\left.\mathrm{MIC}_{90}=0.98-1.95 \mu \mathrm{g} / \mathrm{mL}\right)$. Among the tested substances, compound T7 showed lower activity (MIC $=0.48-7.81 \mu \mathrm{g}$ / $\mathrm{mL}, \mathrm{MIC}_{50}=1.95 \mu \mathrm{g} / \mathrm{mL}$, and $\mathrm{MIC}_{90}=3.91 \mu \mathrm{g} / \mathrm{mL}$ ). It is worth noting that the activity of the new thiazole derivatives against clinical C. albicans isolates was similar to nystatin, used as positive control. This activity was sometimes even stronger than nystatin, especially for compounds T2-T4. These data indicated that a series of nine newly synthesized compounds was very effective towards all studied C. albicans isolated from the oral cavity of patients with hematological malignancies.

Moreover, analyzing the results showed in Table 2, we observed that the studied compounds indicated mainly fungicidal activity (MFC/MIC $=1-4)$ against the tested clinical isolates of $C$. albicans similar to that of nystatin. The fungistatic effect (with values MFC/MIC $=8-16$ ) was observed in a small number of $C$. albicans strains.
Table 1 The activity data $(\mu \mathrm{g} /$ $\mathrm{mL}$ ) of the newly synthesized thiazole derivatives against 30 clinical isolates of $C$. albicans from hospitalized patients with hematological malignancies. The standard antibiotic nystatin (NY) was used as positive control

\begin{tabular}{lllllll}
\hline Compounds & Range of MIC & Range of MFC & $\mathrm{MIC}_{50}$ & $\mathrm{MIC}_{90}$ & $\mathrm{MFC}_{50}$ & $\mathrm{MFC}_{90}$ \\
\hline $\mathrm{T} 1$ & $0.48-3.91$ & $0.98-7.81$ & 0.98 & 1.95 & 1.95 & 7.81 \\
$\mathrm{~T} 2$ & $0.008-0.48$ & $0.015-1.95$ & 0.12 & 0.24 & 0.48 & 0.98 \\
$\mathrm{~T} 3$ & $0.015-0.98$ & $0.06-1.95$ & 0.12 & 0.48 & 0.48 & 1.95 \\
$\mathrm{~T} 4$ & $0.015-0.48$ & $0.06-1.95$ & 0.12 & 0.24 & 0.48 & 1.95 \\
$\mathrm{~T} 5$ & $0.015-1.95$ & $0.03-7.81$ & 0.48 & 0.98 & 1.95 & 3.91 \\
$\mathrm{~T} 6$ & $0.24-1.95$ & $0.24-1.95$ & 0.48 & 0.98 & 0.98 & 1.95 \\
$\mathrm{~T} 7$ & $0.48-7.81$ & $1.95-15.62$ & 1.95 & 3.91 & 7.81 & 15.62 \\
$\mathrm{~T} 8$ & $0.24-3.91$ & $0.48-31.25$ & 0.98 & 1.95 & 3.91 & 7.81 \\
$\mathrm{~T} 9$ & $0.48-3.91$ & $0.48-3.91$ & 0.98 & 1.95 & 1.95 & 3.91 \\
$\mathrm{NY}$ & $0.015-0.48$ & $0.06-0.98$ & 0.12 & 0.24 & 0.24 & 0.48 \\
\hline
\end{tabular}


Table 2 The fungicidal/fungistatic effect of the newly synthesized thiazole derivatives against 30 clinical isolates of $C$. albicans from hospitalized patients with hematological malignancies. The standard antibiotic - nystatin (NY) was used as positive control

\begin{tabular}{|c|c|c|c|c|c|c|c|c|c|c|}
\hline \multirow{2}{*}{$\begin{array}{l}\mathrm{MFC} / \\
\mathrm{MIC} \\
\text { ratio }\end{array}$} & \multicolumn{10}{|c|}{ Number (percentage) of $C$. albicans isolates } \\
\hline & $\mathrm{T} 1$ & $\mathrm{~T} 2$ & T3 & $\mathrm{T} 4$ & $\mathrm{~T} 5$ & T6 & $\mathrm{T} 7$ & $\mathrm{~T} 8$ & T9 & NY \\
\hline 1 & $6(20)$ & - & - & $1(3.33)$ & - & $7(23.33)$ & - & $1(3.33)$ & $3(10)$ & $10(33.33)$ \\
\hline 2 & $18(60)$ & $5(16.66)$ & $11(36.66)$ & $2(6.67)$ & $4(13.33)$ & $20(66.67)$ & $15(50)$ & $14(46.67)$ & $17(56.67)$ & $18(60)$ \\
\hline 4 & $6(20)$ & $20(66.67)$ & $17(56.67)$ & $16(53.33)$ & $19(63.33)$ & $3(10)$ & $14(46.67)$ & $9(30)$ & $10(33.33)$ & $2(6.67)$ \\
\hline 8 & - & $2(6.67)$ & $2(6.67)$ & $8(26.67)$ & $6(20)$ & - & $1(3.33)$ & $4(13.33)$ & - & - \\
\hline 16 & - & $3(10)$ & - & $3(10)$ & $1(3.33)$ & - & - & $2(6.67)$ & - & - \\
\hline
\end{tabular}

\section{Mode of action}

The mechanism of action of the thiazole derivatives was tested in order to define whether the antifungal activity of these compounds involved a direct interaction with the cell wall structure of $C$. albicans (via testing with sorbitol) and/ or with the ion permeability of the membrane of this organism (via the test with ergosterol) (Castro and Lima 2013; de Oliveira Filho et al. 2016).

Sorbitol assay Sorbitol has an osmoprotectant function and is essential for fungal growth, when fungi are in the presence of drugs that act on the cell wall. It is used to stabilize fungi protoplasts, protecting their cell wall from environmental stresses, particularly osmotic changes (Leite et al. 2014; Lima et al. 2012; Rajkowska et al. 2016). As presented in
Fig. 3a, the MIC values of the tested thiazole derivatives in the medium with sorbitol increased 8-32 times against $C$. albicans ATCC 10231 as compared to the cultures in the broth without sorbitol. The similar differences in MICs were also found to occur in the case of C. albicans ATCC 2091. The MICs of the studied compounds increased even 8-64 times in the presence of sorbitol. The MIC of nystatin used as negative control, acting at the level of fungal cell membrane, was not altered in the presence of sorbitol (Fig. 2a).

Based on the ability of sorbitol to act as a fungal cell wall osmotic protective agent, the higher MIC values observed in the medium with added sorbitol compared to the standard medium suggested that the cell wall as one of the possible cell targets for the newly synthesized thiazole derivatives because MIC values of the compounds increased in
Fig. 2 The increase in the MIC values ( $\times$ MIC) of the newly synthesized thiazole derivatives in the presence of a sorbitol $(0.8 \mathrm{M})$ and $\mathbf{b}$ ergosterol $(400 \mu \mathrm{g} / \mathrm{mL})$ against $C$. albicans ATCC 10231 and C. albicans ATCC 2091. The standard antibiotic - nystatin (NY) was used as control

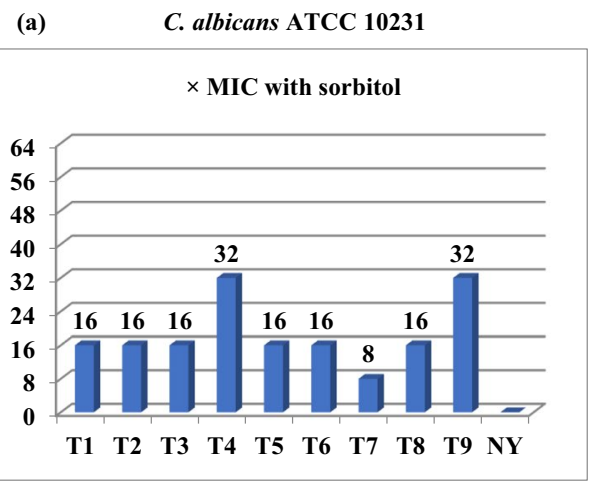

(b) C. albicans ATCC 10231

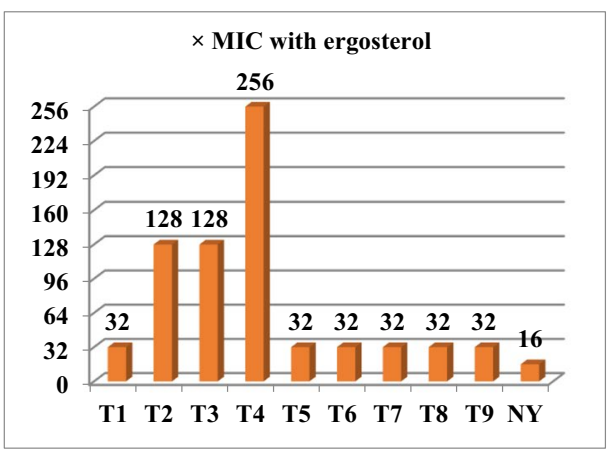

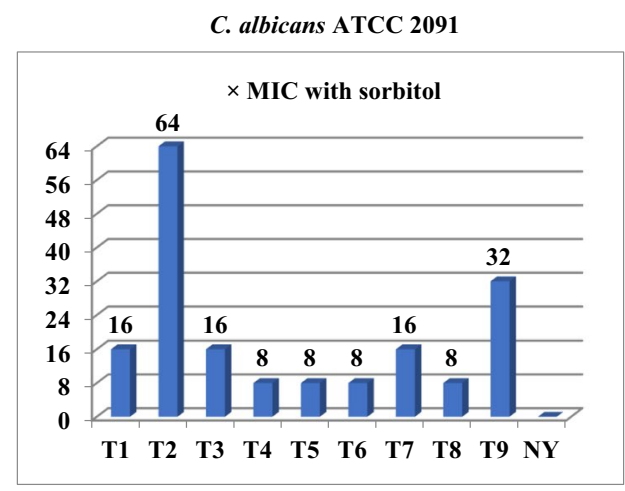

C. albicans ATCC 2091

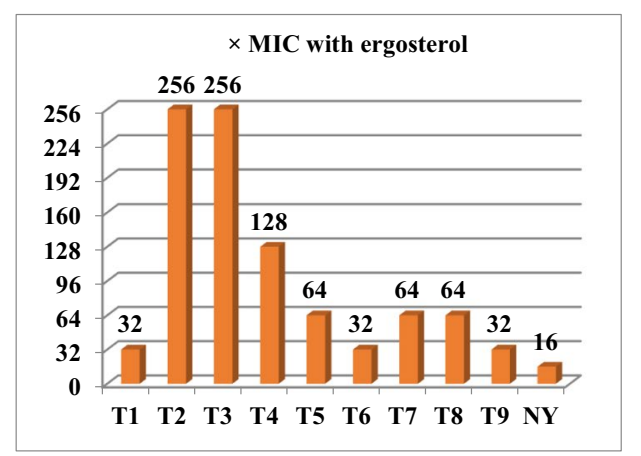


Fig. 3 Hemolytic effect (\% of hemolysis) of the newly synthesized thiazole derivatives

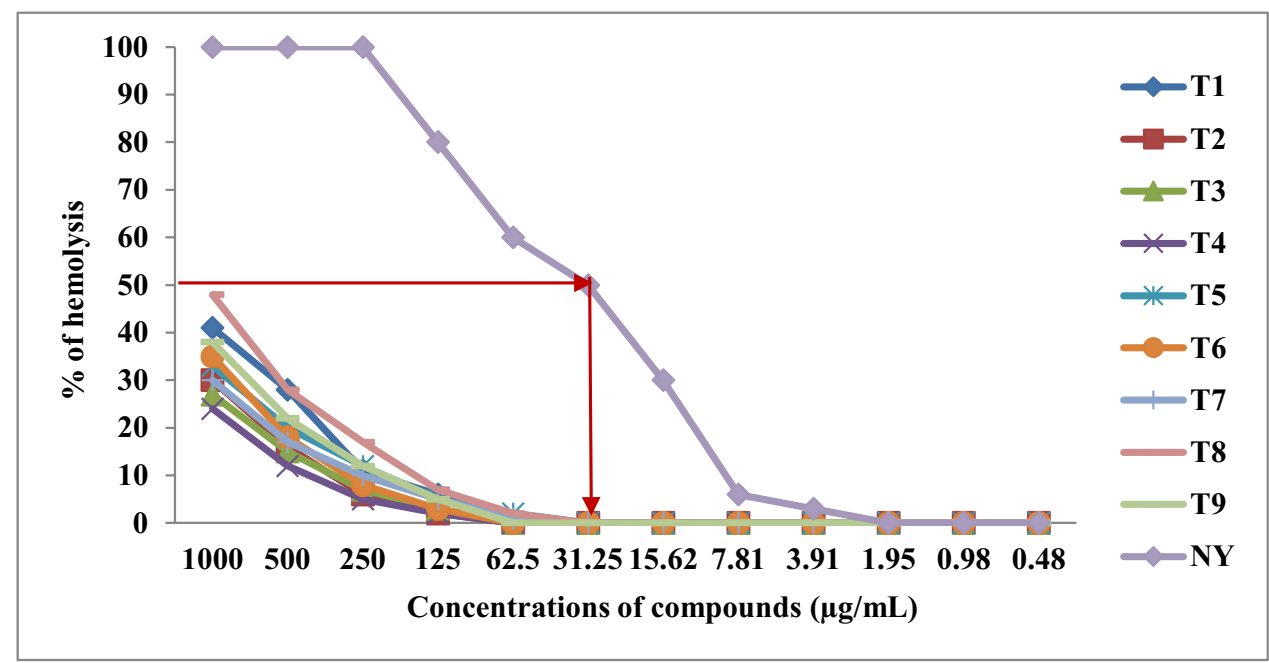

the presence of this osmotic protector (de Oliveira Filho et al. 2016; Rajkowska et al. 2016).

Ergosterol assay Ergosterol and enzymes of the ergosterol biosynthetic pathway are important targets of several classes of antifungals used to treat $C$. albicans infections with a dominant position of the polyenes and the azoles (Rajkowska et al. 2016). The next step of this work was to determine if the studied thiazole derivatives act by affecting ergosterol in the fungal cell membrane.

The obtained results presented in Fig. $2 b$ showed a clear increase in the MIC of the examined compounds in the medium with various concentrations of exogenous ergosterol $(100,200$, and $400 \mu \mathrm{g} / \mathrm{mL})$ compared with the ergosterolfree experiment. MIC values of these compounds and standard antibiotic for both reference $C$. albicans strains increased even 16-256 times in the presence of ergosterol. In the case of most compounds, the MIC values were 32-fold or 64-fold higher. The MIC values of studied compounds increased to the same extent at all concentrations of ergosterol tested. The highest MIC increase was found for compounds T2, T3, and T4 - even 256 times when ergosterol was added to the medium. Perhaps it is related with their high antifungal activity.

We included in the experiment nystatin, whose interaction with fungal cell membrane ergosterol is already known, which served as a positive control (Castro and Lima 2013; Leite et al. 2014; Lima et al. 2012; Turecka et al. 2018). The results showed a 16-fold increase in the nystatin MIC values after the addition of ergosterol, independent on its concentration. These data are consistent with previous studies of Castro and Lima (2013), in which MIC value of this antibiotic against $C$. albicans also increased 16-times in the presence of sterol. The obtained data suggest that the synthesized compounds appear to bind to the ergosterol in the membrane, which increases ion permeability and ultimately results in cell death (Castro and Lima 2013; Turecka et al. 2018). Sorbitol and ergosterol assay data suggest that the newly thiazole derivatives may act not only at the level of fungal cell wall but also at the level of fungal cell membrane.

\section{Investigation of interaction of newly synthesized thiazole derivatives and selected antimycotics}

In the next stage of research, combination of newly synthesized thiazole derivatives with some antifungal drugs (nystatin), synthetic antiseptics (chlorhexidine) or natural substances (thymol) was also assayed for their effect on the growth of reference $C$. albicans strains in order to their define possible interactions. MICs of compounds alone, as well as MICs of combinations which exhibited inhibitory effects, were used to calculate fractional inhibitory concentrations (FICs) and $\Sigma$ FIC (FICI - FIC index) values. To determine the interactions between the tested compounds and the chosen antifungal substances, FIC values were calculated according to the formula given by Blanco et al. (2017).

Our results showed that in combination with the nystatin or chlorhexidine, as presented in Table S1 and Table S2, was observed no growth reduction of MIC values of all studied compounds against both reference $C$. albicans strains. Their values of MICs alone and MICs in combination were the same $($ FIC $=1)$ or differed 2 times $($ FIC $=2)-$ MICs of compounds in combination were 2-fold higher than their MICs alone. The combinations of the studied compounds with nystatin $(\Sigma$ FIC $=2-4)$ and chlorhexidine $(\Sigma$ FIC $=$ 2-3) were found to be noninterfering (FICI values between 1 and 4 were considered as indifferent).

Moreover, these results showed additive effect of compounds $\mathbf{T} 2$ and $\mathbf{T 5}$ in combination with thymol $(\Sigma$ FIC $=1)$ against both reference yeast strains. In turn, in the case of 
C. albicans ATCC 10231, additivity was also indicated for thiazole derivatives $\mathbf{T 3}$ and $\mathbf{T} 7$. The FIC values in all combinations were 0.5 towards both strains, which means a 2-fold decrease MIC values of compounds in combination. For the other derivatives, no interactions was showed (Table S3). These results indicated a good effect of combination of some thiazoles with natural compound-thymol.

\section{Erythrocyte lysis assay}

In the present studies, the erythrocyte model (erythrocyte lysis assay - ELA) was used to assess the effect of the studied compounds on cell membrane. Hemolysis is due to red blood cell destruction which resulted from lysis of membrane lipid bilayer, and it relates with concentration and potency of the studied agents (Han et al. 2016; Zohra and Fawzia 2014). Nystatin was used in this experiment as positive control acting on the level of cell membrane.

As presented in Fig. 3, the highest concentrations of the studied compounds not exerting any hemolytic effects were in the range $31.25-62.5 \mu \mathrm{g} / \mathrm{mL}$, while that of nystatin was $1.95 \mu \mathrm{g} / \mathrm{mL}$. The concentration of nystatin causing $50 \%$ of hemolysis was $31.25 \mu \mathrm{g} / \mathrm{mL}$. In turn, in the case of all newly developed thiazole derivatives, these concentration was above $1000 \mu \mathrm{g} / \mathrm{mL}$. Data obtained using ELA confirm that antifungal effect of the newly synthesized compounds against clinical isolates of $C$. albicans (MIC $=0.008-7.81 \mu \mathrm{g} / \mathrm{mL}$ ) was observed at their non-cytotoxic concentrations.

\section{Lipophilicity determination}

It is well known that chromatographic methods allow fast and reproducible determination of experimental lipophilicity, especially for a wide range of new synthesized compounds. In the present study, the standardization procedure with five reference substances (S1-S5) covering the large range of lipophilicity ( $\log P$ in the range 0.68-6.04) was used. As a result, lipophilicity of S1-S5 was highly correlated with their $R_{M 0}$ values. The coefficients of determination $\left(r^{2}\right)$ for respective regression equations were above 0.93 for three organic modifiers, i.e., acetone, acetonitrile, and methanol. Moreover, the $r^{2}$ values were rather high (above 0.8 ) for the fourth organic modifier, i.e., 1,4-dioxane. Detailed data are available in Table 3.

In addition, correlations between $\log P_{\mathrm{EXP}}$ and $R_{M 0}$ of the reference substances were sufficiently high. The $r^{2}$ values for respective regression equations were above 0.83 for all organic modifiers, i.e., 1,4-dioxane, acetone, acetonitrile, and methanol:

$\log P E X P=1.5180 R M 0-0.7915, r 2=0.8332(1,4-$ dioxane $)$

$\log P E X P=1.3876 R M 0-0.8049, r 2=0.9036($ acetone $)$
Table 3 The $\log P$ and $R_{M 0}$ values of the reference substances (S1S5)

\begin{tabular}{|c|c|c|c|c|c|}
\hline Substance & $\log P$ & $R_{M 0}$ & $S$ & $r^{2}$ & $\varphi$ \\
\hline \multicolumn{6}{|c|}{ 1,4-Dioxane-water } \\
\hline S1 & 0.62 & 1.68 & -0.03 & 0.9204 & 53.63 \\
\hline $\mathrm{S} 2$ & 1.86 & 1.38 & -0.03 & 0.9242 & 51.34 \\
\hline S3 & 2.47 & 1.69 & -0.03 & 0.9917 & 53.48 \\
\hline S4 & 3.80 & 3.46 & -0.05 & 0.8684 & 73.97 \\
\hline S5 & 6.04 & 4.14 & -0.05 & 0.9695 & 79.58 \\
\hline \multicolumn{6}{|c|}{ Acetone-water } \\
\hline $\mathrm{S} 1$ & 0.62 & 1.64 & -0.03 & 0.9452 & 60.29 \\
\hline $\mathrm{S} 2$ & 1.86 & 1.75 & -0.03 & 0.9720 & 58.40 \\
\hline S3 & 2.47 & 1.78 & -0.03 & 0.9380 & 58.77 \\
\hline S4 & 3.80 & 3.61 & -0.05 & 0.9956 & 74.96 \\
\hline S5 & 6.04 & 4.78 & -0.06 & 0.9704 & 82.68 \\
\hline \multicolumn{6}{|c|}{ Acetonitrile-water } \\
\hline S1 & 0.62 & 1.24 & -0.01 & 0.9747 & 65.83 \\
\hline $\mathrm{S} 2$ & 1.86 & 1.73 & -0.03 & 0.9902 & 55.78 \\
\hline S3 & 2.47 & 1.96 & -0.04 & 0.9733 & 53.50 \\
\hline S4 & 3.80 & 2.64 & -0.03 & 0.9899 & 77.28 \\
\hline S5 & 6.04 & 4.26 & -0.05 & 0.9409 & 95.22 \\
\hline \multicolumn{6}{|c|}{ Methanol-water } \\
\hline $\mathrm{S} 1$ & 0.62 & 2.58 & -0.03 & 0.9880 & 82.69 \\
\hline $\mathrm{S} 2$ & 1.86 & 2.18 & -0.03 & 0.9749 & 65.83 \\
\hline S3 & 2.47 & 2.35 & -0.03 & 0.9703 & 68.69 \\
\hline $\mathrm{S} 4$ & 3.80 & 3.61 & -0.04 & 0.9917 & 87.71 \\
\hline S5 & 6.04 & 5.30 & -0.05 & 0.9964 & 103.80 \\
\hline
\end{tabular}

$\log P E X P=1.7467 R M 0-1.1756, r 2=0.9787$ (acetonitrile)

$\log P E X P=1.4576 R M 0-1.7119, r 2=0.8359($ methanol $)$

Similar to the reference compounds, correlations between the $R_{M 0}$ and $R_{F}$ values for newly synthesized thiazole derivatives were sufficiently high $\left(r^{2}>0.91\right)$ for all eluents, providing accuracy for further lipophilicity determination. These data are presented in Table 4.

As far as the experimental lipophilicity of the synthesized compounds was concerned, the highest $\log P$ values were calculated for 1,4-dioxane-water and methanol-water binary mixtures. In the literature, these two organic modifiers were recommended as the most suitable solvents for such estimations (Rutkowska et al. 2013). For all organic modifiers used, i.e., 1,4-dioxane, acetone, acetonitrile, and methanol, the high $\log P$ values was obtained for $\mathbf{T} 2$ derivative containing brome atom as the substituent, while the lowest lipophilicity values were calculated for compounds $\mathbf{T 5}$ and $\mathbf{T} 7$ with methoxy and cyano groups. The mean $\log P$ values of the derivatives lied in the range 3.38-4.49 (Table 5). Generally, it 
Table 4 The $R_{M 0}$ values of the of the newly synthesized thiazole derivatives

\begin{tabular}{|c|c|c|c|c|}
\hline Compound & $R_{M 0}$ & $S$ & $r^{2}$ & $\varphi$ \\
\hline \multicolumn{5}{|c|}{ 1,4-Dioksane-water } \\
\hline $\mathrm{T} 1$ & 3.99 & -0.06 & 0.9290 & 69.58 \\
\hline $\mathrm{T} 2$ & 3.54 & -0.05 & 0.8517 & 73.71 \\
\hline $\mathrm{T} 3$ & 3.46 & -0.05 & 0.8453 & 73.39 \\
\hline $\mathrm{T} 4$ & 3.18 & -0.04 & 0.8154 & 72.23 \\
\hline T5 & 2.83 & -0.04 & 0.7888 & 67.98 \\
\hline T6 & 3.77 & -0.05 & 0.8579 & 73.39 \\
\hline $\mathrm{T} 7$ & 2.93 & -0.04 & 0.8098 & 67.29 \\
\hline $\mathrm{T} 8$ & 3.55 & -0.05 & 0.8255 & 73.88 \\
\hline T9 & 3.14 & -0.05 & 0.7955 & 69.56 \\
\hline \multicolumn{5}{|c|}{ Acetone-water } \\
\hline $\mathrm{T} 1$ & 3.12 & -0.04 & 0.9669 & 71.91 \\
\hline $\mathrm{T} 2$ & 3.62 & -0.05 & 0.9738 & 75.46 \\
\hline $\mathrm{T} 3$ & 3.51 & -0.05 & 0.9831 & 74.66 \\
\hline $\mathrm{T} 4$ & 2.93 & -0.04 & 0.9305 & 73.30 \\
\hline T5 & 2.43 & -0.03 & 0.9147 & 71.08 \\
\hline T6 & 3.67 & -0.05 & 0.9906 & 74.88 \\
\hline $\mathrm{T} 7$ & 2.46 & -0.03 & 0.9618 & 72.29 \\
\hline $\mathrm{T} 8$ & 3.69 & -0.05 & 0.9650 & 75.08 \\
\hline T9 & 3.79 & -0.05 & 0.9901 & 72.33 \\
\hline \multicolumn{5}{|c|}{ Acetonitrile-water } \\
\hline $\mathrm{T} 1$ & 2.62 & -0.03 & 0.9919 & 75.60 \\
\hline $\mathrm{T} 2$ & 3.04 & -0.04 & 0.9983 & 80.64 \\
\hline $\mathrm{T} 3$ & 2.79 & -0.03 & 0.9945 & 80.59 \\
\hline $\mathrm{T} 4$ & 2.60 & -0.03 & 0.9875 & 80.07 \\
\hline T5 & 2.48 & -0.03 & 0.9913 & 75.37 \\
\hline T6 & 2.78 & -0.04 & 0.9869 & 79.53 \\
\hline $\mathrm{T} 7$ & 2.51 & -0.03 & 0.9863 & 72.34 \\
\hline $\mathrm{T} 8$ & 2.81 & -0.04 & 0.9804 & 79.35 \\
\hline T9 & 2.67 & -0.04 & 0.9950 & 74.94 \\
\hline \multicolumn{5}{|c|}{ Methanol-water } \\
\hline $\mathrm{T} 1$ & 4.03 & -0.05 & 0.9911 & 85.38 \\
\hline $\mathrm{T} 2$ & 4.54 & -0.05 & 0.9459 & 90.87 \\
\hline T3 & 4.89 & -0.05 & 0.9883 & 88.71 \\
\hline $\mathrm{T} 4$ & 4.19 & -0.05 & 0.9939 & 89.21 \\
\hline T5 & 4.12 & -0.05 & 0.9933 & 86.75 \\
\hline T6 & 4.94 & -0.06 & 0.9842 & 88.17 \\
\hline $\mathrm{T} 7$ & 3.77 & -0.05 & 0.9953 & 82.03 \\
\hline $\mathrm{T} 8$ & 4.83 & -0.05 & 0.9689 & 88.88 \\
\hline T9 & 4.21 & -0.05 & 0.9920 & 85.22 \\
\hline
\end{tabular}

is known that high lipophilic nature of the compounds facilitates reaching their site of action inside the fungal cells, which was confirmed by the lipophilicity data of the thiazole derivatives.
Table $5 \log P_{\text {EXP }}$ values of the newly synthesized thiazole derivatives calculated using the standardization method

\begin{tabular}{lllll}
\hline Compounds & $\log P_{1,4-\text { dioxane }}$ & $\log P_{\text {acetone }}$ & $\log P_{\text {acetonitrile }}$ & $\log P_{\text {methanol }}$ \\
\hline T1 & 5.27 & 3.53 & 3.40 & 4.15 \\
T2 & 4.58 & 4.22 & 4.13 & 4.91 \\
T3 & 4.47 & 4.06 & 3.70 & 5.42 \\
T4 & 4.03 & 3.26 & 3.36 & 4.40 \\
T5 & 3.50 & 2.57 & 3.16 & 4.30 \\
T6 & 4.93 & 4.29 & 3.69 & 5.49 \\
T7 & 3.66 & 2.61 & 3.20 & 3.79 \\
T8 & 4.59 & 4.32 & 3.74 & 5.33 \\
T9 & 3.98 & 4.45 & 3.49 & 4.43 \\
\hline
\end{tabular}

\section{Discussion}

The incidence of fungal infections has been steadily increasing in recent years (Karpiński 2020). Candida species, especially $C$. albicans, is a common opportunistic fungal pathogen that may cause nosocomial fungal infections, mainly in immunocompromised patients [Gong et al., 2019]. Oropharyngeal candidiasis are the most common fungal infections in these persons [Terças et al. 2017]. Although the antifungal drugs used in clinical treatment appear to be diverse, the list of antimycotics is very limited. Moreover, only few classes of antifungals are currently available to treat infections caused by Candida spp. It is worth adding that many of them have been extensively used and led to the development of antifungal resistance and it brings a great challenge in clinical practice. Therefore, there is a need to search for new antifungals (Sharma et al. 2016; Roemer and Krysan 2014; Turecka et al. 2018; Gong et al. 2019). In view of the high antifungal activity of group of compounds containing the cyclopropane system and their very low toxicity to human cells, we have decided to continue our research on the newly thiazole derivatives (Eaczzowski et al. 2018). In the future, there is a possibility of using them as a new type of antifungal drugs. As a result of studies, we have indicated that novel (2-(cyclopropylmethylidene)hydrazinyl)thiazole showed very strong antifungal activity with MIC $<10 \mu \mathrm{g} /$ $\mathrm{mL}$ (O'Donnell et al., 2010; Wiegand et al. 2008). The values of MIC ranged from 0.008 to $7.81 \mu \mathrm{g} / \mathrm{mL}$ towards, not only reference but also clinical isolates of $C$. albicans from patients with hematological malignancies. These persons are particularly vulnerable to infections, including endogenous candidiasis, that are frequent complications and cause of their morbidity and mortality (Nucci and Anaissie, 2018). Antimicrobial effect of new thiazoles against clinical yeasts was similar to nystatin (used as a control drug), and sometimes even higher than it (especially for compounds T2-T4). In the case of these derivatives, MICs were even below $1 \mu \mathrm{g} /$ $\mathrm{mL}(\mathrm{MIC}=0.008-0.98 \mu \mathrm{g} / \mathrm{mL})$. In turn, MICs below $4 \mu \mathrm{g} /$ 
$\mathrm{mL}$ were showed for the remaining compounds: $\mathbf{T 1}, \mathbf{T 5}, \mathbf{T 6}$, T8, and T9 $(\mathrm{MIC}=0.015-3.91 \mu \mathrm{g} / \mathrm{mL})$. Only compound $\mathbf{T} 7$ indicated slightly lower activity ( $\mathrm{MIC}=7.81 \mu \mathrm{g} / \mathrm{mL}$ ). Our data confirmed that a series of nine new compounds was very effective towards all studied $C$. albicans isolates and these strains were highly sensitive to them.

The results of some research, carried out by other authors (Omran et al. 2018; Eksi et al. 2013; Dagi et al. 2016), showed that conventional antifungal drugs have high and similar activity to our compounds. Namely, strains of $C$. albicans isolated from oropharyngeal infections were susceptible to caspofungin (with MIC = $0.008-1 \mu \mathrm{g} / \mathrm{mL}$ ), amphotericin B (MIC $=0.008-0.25$ $\mu \mathrm{g} / \mathrm{mL}$ ), and azoles: voriconazole, itraconazole, ketokonazole, and posaconazole ( $\mathrm{MIC}=0.016-2 \mu \mathrm{g} / \mathrm{mL}$ ). However, resistance to fluconazole was also observed at $15.5 \%$ C. albicans isolates (MIC $=0.016-16 \mu \mathrm{g} / \mathrm{mL}$ ) (Omran et al. 2018). The data of Eksi et al. (2013) presented also the same effect of amphoterin $\mathrm{B}$, voriconazole (MIC $=0.03-0.25 \mu \mathrm{g} / \mathrm{mL}$ ), and caspofungin (MIC $=0.015-0.25 \mu \mathrm{g} / \mathrm{mL}$ ) against $C$. albicans isolates from the hospitalized patients. The values of MICs of fluconazole were lower $(0.25-32 \mu \mathrm{g} / \mathrm{mL})$. The similar activity towards $C$. albicans isolates from bloodstream showed Dagi et al. (2016) for amphotericin B (MIC $=0.12-1 \mu \mathrm{g}$ / $\mathrm{mL}$ ), azole: fluconazole (MIC $=0.12-2 \mu \mathrm{g} / \mathrm{mL}$ ), voriconazole (MIC $=\leq 0.015-0.06 \mu \mathrm{g} / \mathrm{mL}$ ), posaconazole (MIC $=\leq 0.015-0.12 \mu \mathrm{g} / \mathrm{mL})$, and echinocandins: caspofungin (MIC $=\leq 0.008-0.12 \mu \mathrm{g} / \mathrm{mL}$ ) and anidulafungin (MIC $=0.015-0.12 \mu \mathrm{g} / \mathrm{mL})$. Many authors reported different results regarding susceptibility of $C$. albicans to antifungal agents: high activity of polyenes and echinocandins and decreased susceptibility to azoles. In some studies, resistance rates of $C$. albicans to antimycotics was varied in the range of 3.3-6.7\% for polyene and $0.2-0.5 \%$ for echinocandins [Hedayati et al. 2019; Badiee et al. 2017; Dagi et al. 2016]. In turn, a significant resistance of 56.5-64.5\% to azoles was found. The high use of antimycotics including fluconazole was showed in some hospitals which reported a higher population of patients with hematological malignancies. It has led to azole resistance in a high percentage of $C$. albicans strains which were frequently observed in oropharyngeal candidiasis of these patients (Zaidi et al. 2018).The antifungal agents target three cellular components of fungi. Azoles inhibit the synthesis of ergosterol in the endoplasmic reticulum of the fungal cell. Polyenes bind to ergosterol in the fungal membrane causing disruption of membrane structure and function. Flucytosine is converted within the fungal cell to 5-fluorouracil, which inhibits DNA synthesis [Terças et al. 2017]. The mechanism of action (a direct interaction with the cell wall structure and/or with the ion permeability of the membrane of C. albicans) of the new compounds was also investigated. It is important to know the mode of action of a compound, because this information can be used to increase the effectiveness of the substance and to decrease the selection of resistant strains (Castro and Lima 2013; de Oliveira Filho et al. 2016; Lima et al. 2012). In one of our research studies, sorbitol was used. It is a known osmostabilizer that protects the cell wall from lysis caused by antifungal agents. Sorbitol maintains proper osmotic pressure, thereby providing a suitable environment for the cell wall biosynthesis pathway (Turecka et al. 2018). We also determined whether the tested thiazole derivatives had an effect on ergosterol in the fungal cell membrane. In the case of the most active compounds $\mathbf{T 2}, \mathbf{T 3}$, and $\mathbf{T} 4$ was found the highest (even 128-256 times) increase in MIC values when ergosterol was added to the medium. Moreover, an 8-64-fold increase in their MIC values was showed in the presence of sorbitol. Perhaps it is related with their high antifungal activity. The results indicated that the mechanism of action of studied compounds may be related to their interaction within the cell wall structure of $C$. albicans and within their cell membrane. It is worth noting that the high activity was obtained for $\mathbf{T 2}, \mathbf{T 3}$, and T4 derivatives containing brome atom, chlor atom, and methyl group as the substituent, respectively. Some of them, mainly $\mathbf{T} 2$ derivative, had the high lipophilicity, while the lowest lipophilicity values were calculated for compounds T5 and T7 with methoxy and cyano groups. The high lipophilic nature of the compounds facilitates reaching their site of action inside the fungal cells and increases this activity. Additionally, combination of newly synthesized thiazole derivatives with different antifungal compounds was also assayed for their effect on the growth of reference $C$. albicans strains in order to their define possible interactions. Some compounds (T2, T3, T5, and T7) showed additive effect in combination with the natural substance - thymol. In the case of nystatin (antifungal antibiotic) and chlorhexidine (synthetic antiseptic), no interaction was showed. The combined application of antifungals provides for a reduction of their doses, improves their efficacy, or reduces toxicity. As reported in our previous paper (Łączkowski et al. 2018), the highest possible non-cytotoxic concentration of the newly synthesized thiazole derivatives determined on the cell line model (the mouse L929 fibroblast and the African green monkey kidney - Vero cells) was found to be 7.81-31.25 $\mu \mathrm{g} /$ $\mathrm{mL}$, dependent on the compound. In the present studies, the erythrocytes were used to assess the influence of the tested compounds on their cell membrane. The red blood cell lysis was related with these derivatives in the range of concentrations from 31.25 to $62.5 \mu \mathrm{g} / \mathrm{mL}$. The erythrocyte lysis assay confirmed also the low cytotoxicity of tested compounds. The Candida spp. growth was inhibited at their non-cytotoxic concentrations. In conclusion, all 
reference strains and C. albicans isolates from oral cavity of hospitalized patients with hematological malignancies were susceptible to the novel (2-(cyclopropylmethylidene) hydrazinyl)thiazole at MIC $<10 \mu \mathrm{g} / \mathrm{mL}$. These compounds had a strong anticandidal effect (similar to conventional antimycotics) at non-cytotoxic concentrations. Their mechanism of activity may be associated with the action within the fungal cell wall structure and/or within the cell membrane. Moreover, the high lipophilicity of the derivatives may be related with their high antifungal activity. Therefore, in the field of antifungals, searching new the studied thiazole derivatives appears to be a very promising group of compounds, which may be used, in the future, in the treatment of candidiasis.

Supplementary Information The online version contains supplementary material available at https://doi.org/10.1007/s00253-021-11477-7.

Author contribution Conceptualization: $\mathrm{AB}$; Methodology: $\mathrm{AB}$, ABR, KZŁ; Software: AB; Formal analysis: AB, ABR, AG, KZŁ, MM; Data curation: AB, ABR, KZŁ; Writing-original draft preparation: AB, ABR, AG, KZŁ, JS, AM. All authors read and approved the manuscript.

Data availability Data and material for this article are available upon request.

Code availability Not applicable.

\section{Declarations}

Ethics for approval This article does not contain any studies with human participants or animals performed by any of the authors.

Consent for publication The authors have agreed upon the publication of this manuscript.

Conflict of interest The authors declare no competing interests.

Open Access This article is licensed under a Creative Commons Attribution 4.0 International License, which permits use, sharing, adaptation, distribution and reproduction in any medium or format, as long as you give appropriate credit to the original author(s) and the source, provide a link to the Creative Commons licence, and indicate if changes were made. The images or other third party material in this article are included in the article's Creative Commons licence, unless indicated otherwise in a credit line to the material. If material is not included in the article's Creative Commons licence and your intended use is not permitted by statutory regulation or exceeds the permitted use, you will need to obtain permission directly from the copyright holder. To view a copy of this licence, visit http://creativecommons.org/licenses/by/4.0/.

\section{References}

Abe H, Kikuchi S, Hayakawa K, Iida T, Nagahashi N, Maeda K, Sakamoto J, Matsumoto N, Miura T, Matsumura K, Seki N, Inaba T, Kawasaki H, Yamaguchi T, Kakefuda R, Nanayama T, Kurachi
H, Hori Y, Yoshida T, Kakegawa J, Watanabe Y, Gilmartin AG, Richter MC, Moss KG, Laquerre SC (2011) Discovery of a highly potent and selective MEK inhibitor: GSK1120212 (JTP-74057 DMSO Solvate). ACS Med Chem Lett 2:320-324. https://doi. org $/ 10.1021 / \mathrm{ml} 200004 \mathrm{~g}$

Abu-Melha S, Edrees MM, Riyadh SM, Abdelaziz MR, Elfiky AA, Gomha SM (2020) Clean grinding technique: A facile synthesis and in silico antiviral activity of hydrazones, pyrazoles, and pyrazines bearing thiazole moiety against SARS-CoV-2 Main Protease (Mpro). Molecules 25:4565-4578. https://doi.org/10.3390/molec ules25194565

Badiee P, Badali H, Boekhout T, Diba K, Moghadam AG, Hossaini Nasab A, Jafarian H, Mohammadi R, Mirhendi H, Najafzadeh MJ, Shamsizadeh A, Soltani J (2017) Antifungal susceptibility testing of Candida species isolated from the immunocompromised patients admitted to ten university hospitals in Iran: comparison of colonizing and infecting isolates. BMC Infect Dis 21; 17(1): 727-735. https://doi.org/10.1186/s12879-017-2825-7

Biernasiuk A, Szymańska J, Kustra A, Korona-Głowniak I, Malm A (2018) In vitro susceptibility of oral Candida albicans isolates to chlorhexidine. Acta Pol Pharm 75:795-802

Blanco AR, Nostro A, D'Angelo V, D’Arrigo M, Mazzone MG, Marino A (2017) Efficacy of a fixed combination of tetracycline, chloramphenicol, and colistimethate sodium for treatment of $\mathrm{Can}$ dida albicans keratitis. Invest Ophthalmol vis Sci 58:4292-4298. https://doi.org/10.1167/iovs.17-22047

Carradori S, Secci D, Bolasco A, Rivanera D, Mari E, Zicari A, Lotti LV, Bizzarri B (2013) Synthesis and cytotoxicity of novel (thiazol2-yl)hydrazine derivatives as promising anti-Candida agents. Eur J Med Chem 65:102-111. https://doi.org/10.1016/j.ejmech.2013. 04.042

Castro RD, Lima EO (2013) Anti-Candida activity and chemical composition of Cinnamomum zeylanicum blume essential oil. Braz Arch Biol Technol 56:749-755

Chhabria MT, Patel S, Modi P, Brahmkshatriya PS (2016) Thiazole: a review on chemistry, synthesis and therapeutic importance of its derivatives. Curr Top Med Chem 16:2841-2862. https://doi.org/ 10.2174/1568026616666160506130731

Clinical and Laboratory Standards Institute. Reference method for broth dilution antifungal susceptibility testing of yeasts. M27-S4 (2012). Clinical and Laboratory Standards Institute, Wayne, PA, USA.

Dagi HT, Findik D, Senkeles C, Arslan U (2016) Identification and antifungal susceptibility of Candida species isolated from bloodstream infections in Konya. Turkey Ann Clin Microbiol Antimicrob 15(1):36-41. https://doi.org/10.1186/s12941-016-0153-1

Donarska B, Świtalska M, Płaziński W, Wietrzyk J, Łączkowski KZ (2021) Effect of the dichloro-substitution on antiproliferative activity of phthalimide-thiazole derivatives: rational design, synthesis, elastase, caspase 3/7, and EGFR tyrosine kinase activity and molecular modeling study. Bioorg Chem 110:104819. https:// doi.org/10.1016/j.bioorg.2021.104819

Eschbach E, Scharsack JP, John U, Medlin LK (2001) Improved erythrocyte lysis assay in microtitre plates for sensitive detection and efficient measurement of haemolytic compounds from ichthyotoxic algae. J Appl Toxicol 21:513-519. https://doi.org/10.1002/ jat.797

European Committee for Antimicrobial Susceptibility Testing (EUCAST) determination of minimum inhibitory concentrations (MICs) of antibacterial agents by broth dilution. EUCAST discussion document E. Dis 5.1 (2003) Clin Microbiol Infect 9:1-7.

Eksi F, Gayyurhan ED, Balci I (2013) In vitro susceptibility of Candida species to four antifungal agents assessed by the reference broth microdilution method. Sci World J 2013:236903. https://doi.org/ $10.1155 / 2013 / 236903$ 
Gomha S, Edrees M, Altalbawy F (2016) Synthesis and characterization of some new bis-pyrazolyl-thiazoles incorporating the thiophene moiety as potent anti-tumor agents. Int J Mol Sci 17:1499. https://doi.org/10.3390/ijms17091499

Gong Y, Liu W, Huang X, Hao L, Li Y, Sun S (2019) Antifungal activity and potential mechanism of N-Butylphthalide alone and in combination with fluconazole against Candida albicans. Front Microbiol 10:1461. https://doi.org/10.3389/fmicb.2019.01461

Han J, Jyoti MA, Song HY, Jang WS (2016) Antifungal activity and action mechanism of histatin 5-halocidin hybrid peptides against Candida ssp. PLoS ONE 11:e0150196. https://doi.org/10.1371/ journal.pone.0150196

Hedayati MT, Tavakoli M, Zakavi F, Shokohi T, Mofarrah R, Ansari S, Armaki MT (2019) In vitro antifungal susceptibility of Candida species isolated from diabetic patients. Rev Soc Bras Med Trop 51(4):542-545. https://doi.org/10.1590/0037-8682-0332-2017

Hopkins CD, Schmitz JC, Chu E, Wipf P (2011) Total synthesis of (-)-CP ${ }_{2}$-disorazole $\mathrm{C}_{1}$. Org Lett 13:4088-4091. https://doi.org/10. 1021/ol2015994

Houšł J, Spížek J, Havlíček V (2020) Antifungal Drugs Metabolites 10:106. https://doi.org/10.3390/metabo10030106

Karpiński TM (2020) Essential oils of Lamiaceae family plants as antifungals. Biomolecules 10, 103; https://doi.org/10.3390/biom1 0010103

Komsta $Ł$, Skibiński R, Berecka A, Gumieniczek A, Radkiewicz B, Radoń M (2010) Revisiting thin-layer chromatography as a lipophilicity determination tool - a comparative study on several techniques with a model solute set. J Pharm Biomed Anal 53:911-918. https://doi.org/10.1016/j.jpba.2010.06.024

Konno S, Thanigaimalai P, Yamamoto T, Nakada K, Kakiuchi R, Takayama K, Yamazaki Y, Yakushiji F, Akaji K, Kiso Y, Kawasaki Y, Chen S-E, Freire E, Hayashi Y (2013) Design and synthesis of new tripeptide-type SARS-CoV 3CL protease inhibitors containing an electrophilic arylketone moiety. Bioorg Med Chem 21:412-424. https://doi.org/10.1016/j.bmc.2012.11.017

Leite MC, Bezerra AP, de Sousa JP, Guerra FQ, Lima E de O (2014) Evaluation of antifungal activity and mechanism of action of citral against Candida albicans. Evid Based Complement Alternat Med 378280. https://doi.org/10.1155/2014/378280

Lima IO, de Medeiros Nóbrega F, de Oliveira WA,. Lima E de O, Menezes EA, Cunha FA, Diniz M, de FM (2012) Anti-Candida albicans effectiveness of citral and investigation of mode of action. Pharm Biol 50:1536-1541. https://doi.org/10.3109/13880 209.2012.694893

Łączkowski KZ, Biernasiuk A, Baranowska-Łączkowska A, Zielińska S, Sałat K, Furgała A, Misiura K, Malm A (2016) Synthesis, antimicrobial and anticonvulsant screening of small library of tetrahydro-2H-thiopyran-4-yl based thiazoles and selenazoles. J Enzyme Inhib Med Chem 31:24-39. https://doi.org/10.1080/ 14756366.2016.1186020

Łączkowski KZ, Konklewska N, Biernasiuk A, Malm A, Sałat K, Furgała A, Dzitko K, Bekier A, Baranowska-Łączkowska A, Paneth A (2018) Thiazoles with cyclopropyl fragment as antifungal, anticonvulsant, and anti-Toxoplasma gondii agents: synthesis, toxicity evaluation, and molecular docking study. Med Chem Res 27:2125-2140

Łączkowski KZ, Landowska K, Biernasiuk A, Sałat K, Furgała A, Plech T, Malm A (2017) Synthesis, biological evaluation and molecular docking studies of novel quinuclidinone derivatives as potential antimicrobial and anticonvulsant agents. Med Chem Res 26:2088-2104

Makam P, Thakur PK, Kannan T (2014) In vitro and in silico antimalarial activity of 2-(2-hydrazinyl)thiazole derivatives. Eur J Pharm Sci 52:138-145. https://doi.org/10.1016/j.ejps.2013.11.001

Nucci M, Anaissie EJ (2018) Prevention of infections in patients with hematological malignancies. in: Wiernik P, Dutcher J, Gertz M (eds) Neoplastic diseases of the blood. Springer, Cham. https:// doi.org/10.1007/978-3-319-64263-5_49

O’Donnell F, Smyth TJ, Ramachandran VT, Smyth WF (2010) A study of the antimicrobial activity of selected synthetic and naturally occurring quinolones. Int J Antimicrob Agents 35:30-38. https:// doi.org/10.1016/j.ijantimicag.2009.06.031

de Oliveira Filho AA, de Oliveira HMBF, de Sousa JP, Meireles D, de Azevedo Maia GL, Filho JMB, Lima EO (2016) In vitro antiCandida activity and mechanism of action of the flavonoid isolated from Praxelis clematidea against Candida albicans species. J App Pharm Sci 6:66-69

de Oliveira Filho GB, Cardoso MVDO, Espíndola JWP, Oliveira de Silva DA, Ferreira RS, Coelho PL, Anjos PSD, Santos EDS, Meira CS, Moreira DRM, Soares MBP, Leite ACL (2017) Structural design, synthesis and pharmacological evaluation of thiazoles against Trypanosoma cruzi. Eur J Med Chem 141:346-361. https://doi.org/10.1016/j.ejmech.2017.09.047

Omran MS, Dastjerdi RM, Zuashkiani M, Moqarabzadeh V, Taghizadeh-Armaki M (2018) In vitro antifungal susceptibility of Candida species isolated from iranian patients with denture stomatitis. Biomed Res Int 2018:3086586. https://doi.org/10.1155/2018/ 3086586

Piechowska K, Świtalska M, Cytarska J, Jaroch K, Łuczykowski K, Chałupka J, Wietrzyk J, Misiura K, Bojko B, Kruszewski S, Łączkowski KZ (2019) Discovery of tropinone-thiazole derivatives as potent caspase $3 / 7$ activators, and noncompetitive tyrosinase inhibitors with high antiproliferative activity: Rational design, one-pot tricomponent synthesis, and lipophilicity determination. Eur J Med Chem 175:162-171. https://doi.org/10.1016/j. ejmech.2019.05.006

Pristov KE, Ghannoum MA (2019) Resistance of Candida to azoles and echinocandins worldwide. Clin Microbiol Infect 25:792-798. https://doi.org/10.1016/j.cmi.2019.03.028

Rajkowska K, Nowak A, Kunicka-Styczyńska A, Siadur A (2016) Biological effects of various chemically characterized essential oils: investigation of the mode of action against Candida albicans and HeLa cells. RSC Adv 6:97199-97207

Roemer T, Krysan DJ (2014) Antifungal drug development: challenges, unmet clinical needs, and new approaches. Cold Spring Harb Perspect Med 4 pii:a019703. doi: https://doi.org/10.1101/ cshperspect.a019703

Rutkowska E, Pająk K, Jóźwiak K (2013) Lipophilicity - methods of determination and its role in medicinal chemistry. Acta Pol Pharm - Drug Res 70:3-18

Salar U, Khan KM, Chigurupati S, Syed S, Vijayabalan S, Wadood A, Riaz M, Ghufran M, Perveen S (2019) New hybrid scaffolds based on hydrazinyl thiazole substituted coumarin; As novel leads of dual potential; in vitro $\alpha$-amylase inhibitory and antioxidant (DPPH and ABTS radical scavenging) activities. Med Chem 15:87-101. https://doi.org/10.2174/15734064146661809031 62243

Sharma Y, Khan LA, Manzoor N (2016) Anti-Candida activity of geraniol involves disruption of cell membrane integrity and function. J Mycol Med 26:244-254. https://doi.org/10.1016/j.mycmed. 2016.04.004

Silva S, Rodrigues CF, Araújo D, Rodrigues ME, Henriques M (2017) Candida species biofilms' antifungal resistance. J Fungi 3:8-24. https://doi.org/10.3390/jof3010008

Siddiqui AA, Partap S, Khisal S, Yar MS, Mishra R (2020) Synthesis, anti-convulsant activity and molecular docking study of novel thiazole pyridazinone hybrid analogues. Bioorg Chem 99:103584. https://doi.org/10.1016/j.bioorg.2020.103584

Sun L, Liao K, Wang D (2015) Effects of magnolol and honokiol on adhesion, yeast-hyphal transition, and formation of biofilm by Candida albicans. PLoS ONE 10:e0117695. https://doi.org/10. 1371/journal.pone.0117695 
Talele TT (2016) The "cyclopropyl fragment" is a versatile player that frequently appears in preclinical/clinical drug molecules. J Med Chem 59:8712-8756. https://doi.org/10.1021/acs.jmedchem. $6 \mathrm{~b} 00472$

Terças AL, Marques SG, Moffa EB, Alves MB, de Azevedo CM, Siqueira WL, Monteiro CA (2017) Antifungal drug susceptibility of Candida species isolated from HIV-positive patients recruited at a public hospital in São Luís, Maranhão. Brazil Front Microbiol 2(8):298. https://doi.org/10.3389/fmicb.2017.00298

Turecka K, Chylewska A, Kawiak A, Waleron KF (2018) Antifungal activity and mechanism of action of the $\mathrm{Co}$ (III) coordination complexes with diamine chelate ligands against reference and clinical strains of Candida spp. Front Microbiol 9:1954-1607. https://doi. org/10.3389/fmicb.2018.01594

Viegas-Junior C, Danuello A, da Silva BV, Barreiro EJ, Manssour Fraga CA (2007) Molecular hybridization: a useful tool in the design of new drug prototypes. Curr Med Chem 14:1829-1852. https://doi.org/10.2174/092986707781058805

Wiegand I, Hilpert K, Hancock REW (2008) Agar and broth dilution methods to determine the minimal inhibitory concentration (MIC) of antimicrobial substances. Nat Protoc 3:163-175. https://doi. org/10.1038/nprot.2007.521

Wood MR, Schirripa KM, Kim JJ, Wan B-L, Murphy KL, Random RW, Chang RSL, Tang C, Prueksaritanont T, Detwiler TJ, Hettrick LA, Landis ER, Leonard YM, Krueger JA, Lewis SD, Pettibone DJ, Freidinger RM, Bock MG (2006) Cyclopropylamino acid amide as a pharmacophoric replacement for 2,3-diaminopyridine. Application to the design of novel bradykinin B1 receptor antagonists. J Med Chem 49:1231-1234

Zaidi KU, Mani A, Parmar R, Thawan V (2018) Antifungal susceptibility pattern of Candida albicans in human infections. Open Biol Sci J 4:1-6

Zohra M, Fawzia A (2014) Hemolytic activity of different herbal extracts used in Algeria. Int J Pharm Sci Res 5:495-500

Publisher's note Springer Nature remains neutral with regard to jurisdictional claims in published maps and institutional affiliations.

\section{Authors and Affiliations}

\section{Anna Biernasiuk ${ }^{1}$ (D) Anna Berecka-Rycerz ${ }^{2} \cdot$ Anna Gumieniczek $^{2} \cdot$ Maria Malm $^{3} \cdot \mathrm{Krzysztof} \mathrm{Z.} \mathrm{Łączkowski}^{4}$. Jolanta Szymańska ${ }^{5}$ Anna Malm ${ }^{1}$}

\author{
Anna Berecka-Rycerz \\ anna.berecka@umlub.pl \\ Anna Gumieniczek \\ anna.gumieniczek@umlub.pl \\ Maria Malm \\ maria.malm@umlub.pl
}

Krzysztof Z. Łączkowski

krzysztof.laczkowski@cm.umk.pl

Jolanta Szymańska

jolanta.szymanska@umlub.pl

Anna Malm

anna.malm@umlub.pl

1 Department of Pharmaceutical Microbiology, Faculty of Pharmacy, Medical University of Lublin, Chodźki 1, 20-093 Lublin, Poland
2 Department of Medicinal Chemistry, Faculty of Pharmacy, Medical University of Lublin, Jaczewskiego 4, 20-090 Lublin, Poland

3 Department of Medicinal Informatics and Statistics with E-Learning Lab, Faculty of Health Sciences, Medical University of Lublin, Jaczewskiego 4, Lublin 20-090, Poland

4 Department of Chemical Technology and Pharmaceuticals, Faculty of Pharmacy, Collegium Medicum, Nicolaus Copernicus University, Jurasza 2, 85-089 Bydgoszcz, Poland

5 Department of Integrated Paediatric Dentistry, Chair of Integrated Dentistry, Faculty of Medical Dentistry, Medical University of Lublin, Lubartowska 58, 20-94 Lublin, Poland 